CLINICAL CASE

\title{
DIFFERENT SURGICAL OPTIONS IN CUSHING'S DISEASE
}

\author{
Ana Valea ${ }^{1,2}$, Cristina Ghervan ${ }^{1,2}$, Mara Carsote $^{3,4}$, Simona Elena Albu ${ }^{3,5}$, Carmen Emanuela \\ Georgescu, ${ }^{1,2}$ \\ ${ }^{1}$ The University of Medicine and Pharmacy "Iuliu Hatieganu", Cluj-Napoca, Romania \\ ${ }^{2}$ Clinical County Hospital, Cluj-Napoca, Romania \\ ${ }^{3}$ The University of Medicine and Pharmacy "Carol Davila", Bucharest, Romania \\ 4“C.I. Parhon” National Institute of Endocrinology, Bucharest, Romania \\ ${ }^{5}$ The University Emergency Hospital, Bucharest, Romania
}

Corresponding author: Mara Carsote

Phone no. 0040213172041

E-mail: carsote_m@hotmail.com

\begin{abstract}
Cushing's disease represents a severe endocrine disorder caused by prolonged exposure to pituitary tumor-related high cortisol levels. Pituitary surgery is not always successful and other approaches as radiotherapy, direct suppressors of adrenocortical and/or pituitary activity, bilateral adrenalectomy are necessary. Case report 1 - A 15-year-old female was admitted at the age of 14 for secondary amenorrhea, weight gain and emotional disturbances. Pituitary MRI revealed 2 microadenomas of $3 \mathrm{~mm}$, respective $3.5 \mathrm{~mm}$. The pathological report confirmed benign features. After 12 days of hospitalization, the patient was discharged with the recommendation of levothyroxine. Within the first year after surgery, the thyroid insufficiency due to pituitary surgery remitted. Case report 2 - A 66-year-old male presented at the age of 37 with headache, weight gain, high blood pressure and Cushing's disease was confirmed. Pituitary radiotherapy was preferred to pituitary surgery since no pituitary tumor was revealed at imagery. 3 years later, two times open bilateral adrenalectomy was performed due to persistent hypercortisolism. The histology exam revealed bilateral adrenal hyperplasia. After discharge, lifelong therapy for adrenal insufficiency was required. 32 months later, the clinical picture was complicated with Nelson's syndrome based on skin hyper-pigmentation and high ACTH (Adrenocorticotropic Hormone) despite no obvious pituitary adenoma was revealed by imagery. Weekly cabergoline was introduced to correct the increased ACTH. Transsphenoidal hypophysectomy represents the treatment of choice for ACTHproducing pituitary tumors. The cases when pituitary surgery is not optional or successful, a second surgical procedure as bilateral adrenalectomy might become necessary.
\end{abstract}

Keywords: Cushing's disease, pituitary tumor, transsphenoidal hypophysectomy, adrenalectomy, hypercortisolism

\section{Introduction}

Cushing's disease represents a severe endocrine condition caused by prolonged exposure to elevated cortisol due to an Adrenocorticotropic Hormone (ACTH)- producing tumor [1]. Although pituitary surgery is the golden standard therapy, there are cases when this is not successful [2]. In such situations, repeated pituitary surgery is an alternative [3-5]. Direct suppression of tumor by pituitary radiotherapy (conventional or 
stereotaxic) or by drugs (somatostatin analogs such as pasireotide or dopaminergic agonists like cabergoline) may be used $[5,6,7,8]$. Inhibition of adrenal steroidogenesis with ketoconazole or metyrapone, or adrenolytic agents, for instance, mitotane are useful in selected cases $[9,10]$. Adrenal surgery (bilateral adrenalectomy) represents a surgical alternative if no response to previous options was seen $[11,12]$. In daily practice, the therapy is challenging for most of the cases because it is difficult to achieve a high success rate, a rapid disease control, a normal pituitary and adrenal axis, and a good tolerability of medication. Close follow-up of the adrenal status is necessary.

We present a series of 2 patients diagnosed with Cushing's disease who benefit by 2 different surgical approaches. Their informed written consent was obtained.

\section{Presentation of cases}

\section{Case report 1}

A 15-year-old non-smoking female, with irrelevant medical family history, was admitted for secondary amenorrhea, weight gain $(15 \mathrm{~kg}$ during the last year) with central obesity distribution, „full moon" face, buffalo hump, abdominal purple striae with a typical Cushinglike pattern, axillary and cervical acanthosis nigricans, acne and hirsutism (FerrimanGallwey score of 10) and emotional disturbances. The endocrine evaluation revealed high levels of serum and free urinary cortisol (UFC), non- suppression at dexamethasone (DXM) $1 \mathrm{mg}$ overnight test and 50\% suppression at high dose of DXM test. Based on these, Cushing's disease was confirmed without any radiological evidence of a pituitary mass. 3 months later pituitary MRI (Magnetic Resonance Imagery) with IV contrast showed the presence of 2 microadenomas of $3 \mathrm{~mm}$, respective $3.5 \mathrm{~mm}$ (Figure $1 \mathrm{~A}+\mathrm{B}$ ). Transsphenoidal hypophysectomy was performed 2 months later. No complications were reported intra or post-operatively. The pathological report revealed a pituitary adenoma with intense cellular pleomorphism, eosinophilic cytoplasm, and clear cell limits. The subjects was hospitalized for 12 days and, after discharge, she was treated with $50 \mu \mathrm{g}$ of daily LT4 (Levothyroxine).

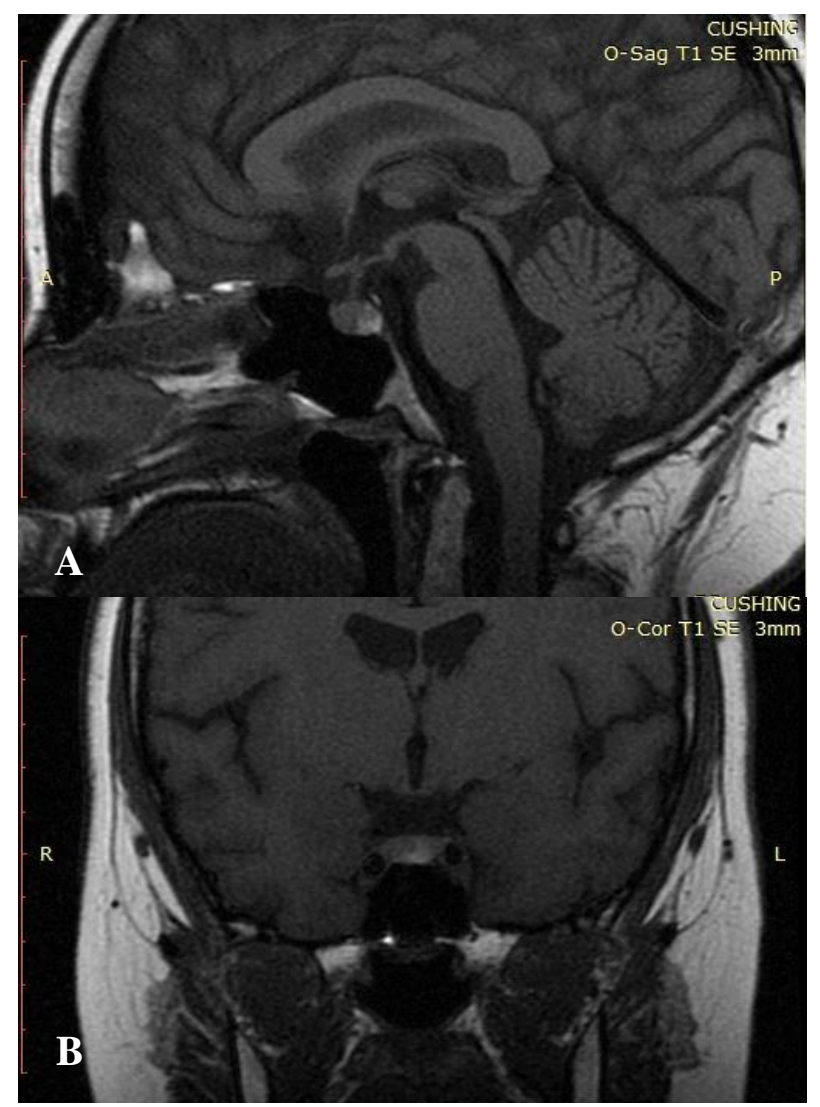

Figure 1 - IV Contrast MRI performed preoperatively on a 14-year-old female: two sellar microadenomas of $3 \mathrm{~mm}$, and $3.5 \mathrm{~mm}$ respectively (A - Sagital Plane, B - Coronal plane)

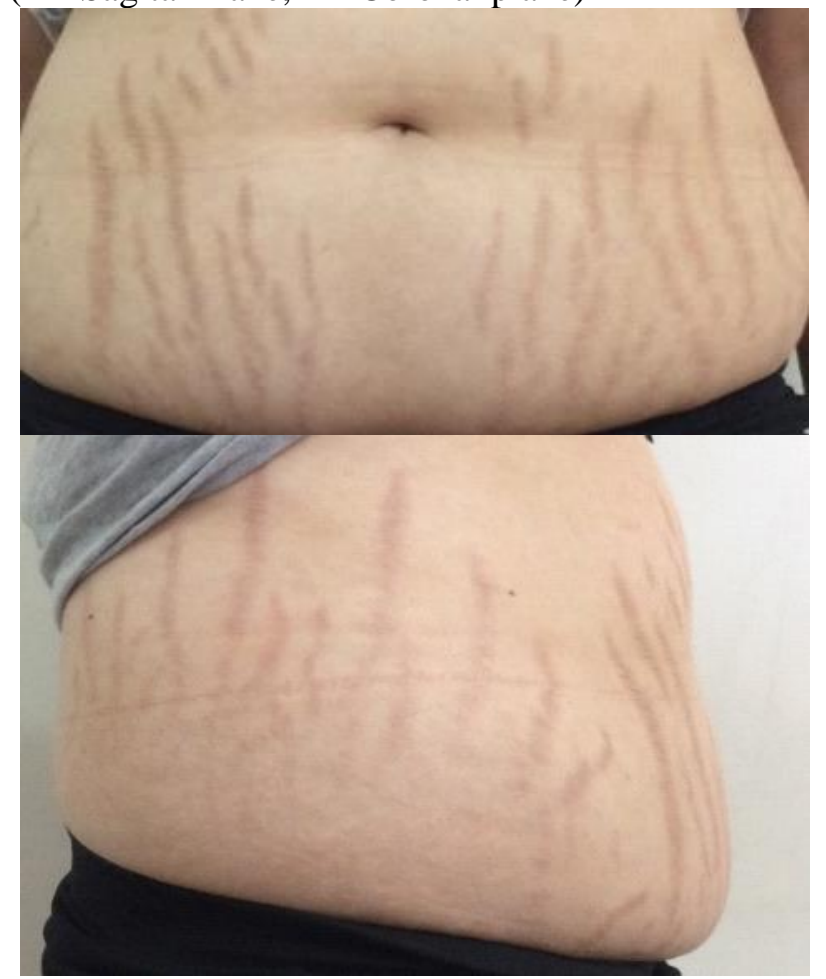

Figure 2 - Cushing disease on a young female subject: abdominal striae. Note the pale aspect 1 year after pituitary surgery 


\begin{tabular}{|c|c|c|c|c|c|c|}
\hline Parameter & $\begin{array}{c}\text { before } \\
\text { surgery }\end{array}$ & $\begin{array}{c}6 \text { weeks } \\
\text { after surgery }\end{array}$ & $\begin{array}{c}4 \text { months } \\
\text { after surgery }\end{array}$ & $\begin{array}{c}12 \text { months } \\
\text { after surgery }\end{array}$ & $\begin{array}{c}\text { Normal } \\
\text { limits }\end{array}$ & Units \\
\hline $\begin{array}{l}\text { Plasma Cortisol } \\
(8 \text { a.m) }\end{array}$ & 28.2 & 0.9 & 6.1 & 5.8 & $5-25$ & $\mu g / d L$ \\
\hline $\begin{array}{l}\text { Plasma Cortisol } \\
\text { (8 p.m) }\end{array}$ & 22.6 & 0.6 & 1.8 & 1.7 & $5-13$ & $\mu g / d L$ \\
\hline UFC & 319.6 & NA* & 112 & 98 & $50-190$ & $\mu g / 24 h$ \\
\hline ACTH & 59.99 & 12.14 & 20.83 & 21.6 & $7.2-63.3$ & $\mathrm{pg} / \mathrm{mL}$ \\
\hline TSH & 1.67 & $0.88 * *$ & 1.04 & 0.65 & 0.4-4 & $\boldsymbol{\mu U} \mathbf{I} / \mathbf{m L}$ \\
\hline FreeT4 & 1.13 & $1.69 * *$ & 1.54 & 1.45 & $0.89-1.76$ & ng/dL \\
\hline Progesterone & NA & 0.45 & 1.82 & 2.6 & 4-25 & $\mathrm{ng} / \mathrm{mL}$ \\
\hline Estradiol & 32 & 74.1 & 56 & 86.2 & $27-250$ & $\mathrm{pg} / \mathrm{mL}$ \\
\hline Prl & NA & 4.6 & 6.76 & 7.4 & $1.3-20$ & $\mathrm{ng} / \mathrm{mL}$ \\
\hline FSH & $\mathbf{N A}$ & 4.7 & 7.8 & 6.8 & 2.8-11.3 & $\mathbf{U} / \mathbf{L}$ \\
\hline LH & NA & 3.4 & 4.5 & 5 & $1-11.5$ & $\mathbf{U} / \mathbf{L}$ \\
\hline
\end{tabular}

* not available; ** under daily levothyroxine therapy

Table 1 - The endocrine parameters of a female patient diagnosed (at the age of 14) and treated for Cushing disease: before and after transsphenoidal hypophysectomy

\begin{tabular}{|c|c|c|c|c|c|c|}
\hline Parameter & Initially\# & $\begin{array}{l}\text { After } 3 \\
\text { months }\end{array}$ & $\begin{array}{l}\text { After } 6 \\
\text { months }\end{array}$ & $\begin{array}{l}\text { After } 12 \\
\text { months }\end{array}$ & $\begin{array}{c}\text { Normal } \\
\text { limits }\end{array}$ & Units \\
\hline ACTH & $>1250$ & 715 & $>1250$ & $>120$ & $7.2-63.3$ & $\mathrm{pg} / \mathrm{mL}$ \\
\hline TSH & $1.17 *$ & $1.49 *$ & $2.28 *$ & 1.39* & $0.4-4$ & $\mu \mathrm{UI} / \mathrm{mL}$ \\
\hline FreeT4 & $1.20 *$ & $1.27 *$ & $1.13 *$ & $1.14 *$ & $0.89-1.76$ & ng/dL \\
\hline Prl & 12.9 & 4.42 & 6.76 & 10.1 & 1.8-17 & ng/mL \\
\hline Testosterone & $3.8 * *$ & $4.2 * *$ & $4.6 * *$ & $5.87 * *$ & 1.8-9 & $\mathrm{ng} / \mathrm{mL}$ \\
\hline $\mathbf{N a}$ & 116 & 134 & 133 & 133 & $136-145$ & $\mathrm{mEq} / \mathrm{L}$ \\
\hline $\mathbf{K}$ & 5.8 & 4 & 4.5 & 4.1 & $3.5-5.1$ & $\mathrm{mEq} / \mathrm{L}$ \\
\hline
\end{tabular}

\# age of 58; * under daily levothyroxine for central hypothyroidism due to irradiation; **under testosterone therapy for central hypogonadism due to irradiation

Table 2 - The endocrine parameters on a male patient diagnosed with Cushing's disease at the age of 37: at the age of 38 pituitary irradiation was performed, 3 years later bilateral adrenalectomy was done. The endocrine panel is displayed since the age of 58 years when he was admitted on a tertiary Center of Endocrinology for Nelson's syndrome

The hormonal tests were performed 6 weeks after surgery and they revealed normal adrenal axes (Table 1). Normal thyroid test rules out a central thyroid insufficiency so LT4 therapy was stopped (Table 1). MRI scan performed 4 months after surgery revealed a pituitary gland of 0.87 by 0.30 by $0.67 \mathrm{~cm}$, without any tumor. Hormonal profile showed normal values of prolactin, ACTH, FreeT4, except for hypogonadism which required progesteron administration (10 mg daily, 10 day per month). 1 one year post-operatively normal endocrine profile was found in association with clinical improvement: weight loss (of $19 \mathrm{~kg}$ ) and fading of striae (Figure 2). Periodical revaluation is recommended.

\section{Case report 2}

A 66-year-old non-smoking male is known with a medical history of gallstones, and hyperlipemia. The family history is positive for breast cancer (sister) and high blood pressure with stroke (father). At the age of 37 he accused dizziness, headache, arterial hypertension, progressive weight gain and endocrine evaluation confirmed Cushing disease. Imagery did not reveal the pituitary tumor so pituitary radiotherapy (conventional cobalt therapy) was offered at the age of 38.3 years later, the disease was still active so two times open bilateral adrenalectomy was performed during one hospitalization of 56 days (an interval of 45 days between the two surgical 
interventions). No significant intra-operatory complications were reported. The histology revealed bilateral adrenal hyperplasia. After discharge, chronic adrenal insufficiency required daily prednisone, fludrocortisones. He also was treated with testosterone and levothyroxine for pituitary insufficiency due to irradiation. 32 months later, a Nelson's syndrome as suspected based on pigmented skin and high ACTH. No obvious pituitary adenoma was found on MRI examination. Weekly cabergoline was started to correct the ACTH levels. For the next 2 decades, he was followedup only based on clinical exam, blood ionogram and hormonal tests in different endocrine centers (Table 2).

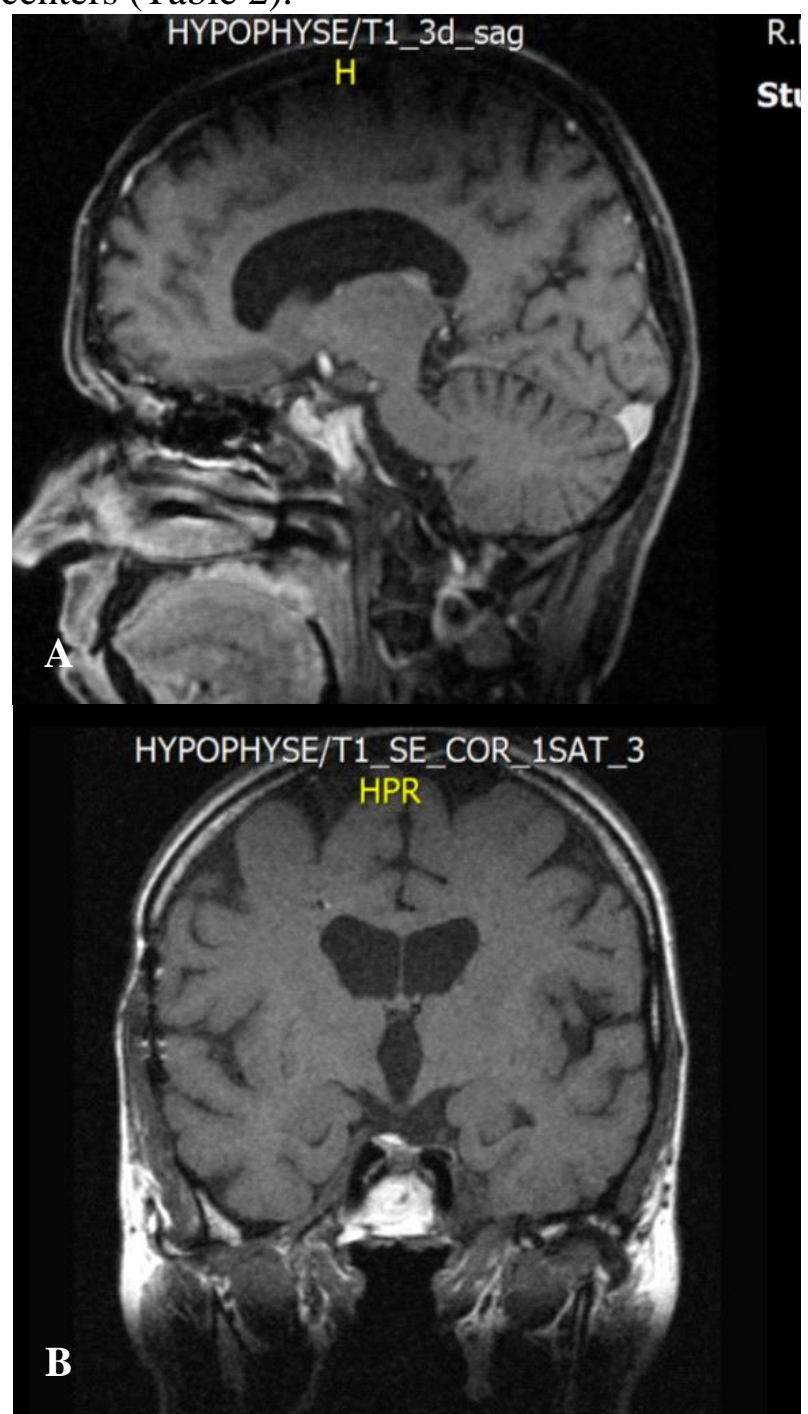

Figure 3 - IV Contrast MRI performed 21 years after conventional radiotherapy on an adult male: no tumor mass at the level of the pituitary gland despite high values of ACTH (consistent with Nelson's syndrome) (A - Sagittal plane, B - Coronal plane)

21 years since the first diagnosis, the patient was admitted for a detailed endocrine assessment at a Tertiary Romanian Center of Endocrinology. The subject complained of arterial pressure variations, chronic asthenia, discrete pigmentation skin, unspecific muscle and joints pain. Blood tests revealed normal serum ionogram under $7.5 \mathrm{mg}$ prednisone and $0.2 \mathrm{mg}$ fludrocortizone. Hormonal profile showed normal values for prolactin, TSH, FT4 under LT4 substitution (75 $\mu \mathrm{g}$ daily) and high values of ACTH, consistent with Nelson's syndrome (Table 2). MRI with IV contrast did not evidence o pituitary mass (Figure 3 ). The eye exam was also normal. CT scan of lungs and abdomen excluded an ectopic ACTH production. Cabergoline of $2 \mathrm{mg}$ per week was offered. After 3 months of treatment ACTH decreased from $1250 \mathrm{pg} / \mathrm{mL}$ (normal ranges between 7.2 and $63.3 \mathrm{pg} / \mathrm{mL}$ ) to $715 \mathrm{pg} / \mathrm{mL}$. Further close check-up is periodically advised.

\section{Discussions}

Both of these patients had Cushing's disease and the ACTH-producing pituitary tumors were not visible on MRI at first admission. This is found on $40 \%$ of cases [13]. The female case has a medical and surgical history of more than 1 year. After hypophysectomy, gonadal insufficiency was the only anomaly presented. Varying degrees of postoperative hypopituitarism are seen in $30-40 \%$ of all cases particularly if surgery is carried out blindly [14]. In this case hypothyroidism was transient so thyroxine replacemet therapy was discontinued 4 months after surgery.

The male case presents the data we obtained after more than three decades since the diagnosis of disease. Because the patient first refused blindly pituitary surgery, radiotherapy was performed with secondary hypogonadism and hypothyroidism. Persistent hypercortisolism and the occurrence of diabetes as a complication of the disease made bilateral adrenalectomy necessary. Generally, Nelson's syndrome, characterized by accelerated growth of the pituitary tumor and ACTH occurs in $8-38 \%$ of patients with Cushing's disease after bilateral adrenalectomy, 7-24 years after surgery [15]. In our case, the diagnosis was first established 32 months after adrenal surgery but, with a rare pattern, without any suggestive image for 
pituitary adenoma on MRI scan. Pituitary surgery was not optional, so dopaminergic agonists as cabergoline may be tried.

\section{Conclusions}

Transsphenoidal hypophysectomy represents the treatment of choice for Cushing's disease. After the procedure, a good outcome is expected. In cases with persistence or late recurrence of hypercortisolism after pituitary surgery, either radiotherapy, pituitary and/or adrenal targeted drugs or bilateral adrenalectomy are necessary. Unfortunately, this last mentioned surgical procedure required lifelong adrenal substitution therapy. Moreover, a rare but severe complication, Nelson's syndrome, is a challenge situation due to limited therapeutically options.

\section{References}

[1]Raff H, Carroll T. Cushing's syndrome: from physiological principles to diagnosis and clinical care.J Physiol. 2015; 593(Pt 3): 493-506.

[2]Nieman LK, Biller BMK, Findling JW, et al. The Diagnosis of Cushing's Syndrome: An Endocrine Society Clinical Practice Guideline. J Clin Endocrinol Metab 2008;93(5):1526-1540.

[3]Zhang N, Pan L, Dai J et al. Gamma knife radiosurgery as a primary surgical treatment for hypersecreting pituitary adenoma. Stereotact Funct Neurosurg 2000;75:123-8.

[4]Cuevas-Ramos D, Fleseriu M. Treatment of Cushing's disease: a mechanistic update. Journal of Endocrinology 2014;223:R19-R39.
[5]Colao A, Petersenn S, Newell-Price J, et al. A 12month phase 3 study of pasireotide in Cushing's disease. N Engl J Med. 2012;366:914-924.

[6]Biller BM, Grossman AB, Stewart PM, et al. Treatment of adrenocorticotropin-dependent Cushing's syndrome: a consensus statement. J Clin Endocrinol Metab. 2008;93:2454-2462.

[7]Feelders RA, Hofland LJ. Medical treatment of Cushing's disease. J Clin Endocrinol Metab. 2013;98:425-438.

[8]Castinetti F, Guignat L, Giraud P, Muller M, et all. Ketoconazole in Cushing's Disease: Is It Worth a Try?.J Clin Endocrinol Metab.2014; 99: 16231630.

[9]Bertagna X, Guignat L. Approach to the Cushing's disease patient with persistent/recurrent hypercortisolism after pituitary surgery. J Clin Endocrinol Metab. 2013;98:1307-1318.

[10]Pivonello R, De Leo M, Cozzolino A, Colao A. The Treatment of Cushing's Disease.Endocr Rev. 2015; 36(4): 385-486.

[11]Tiyadatah BN, Kalavampara SV, Sukumar S, et al. Bilateral simultaneous laparoscopic adrenalectomy in Cushing's syndrome: safe, effective, and curative. J Endourol. 2012;26:157163.

[12]Katznelson L, Loriaux DL, Feldma D, Glenn D, et al. Global Clinical Response in Cushing's Syndrome Patients Treated with Mifepristone. Clin Endocrinol. 2014;80(4):562-569.

[13]Feelders RA, Pulgar SJ, Kempel A, Pereira AM. The burden of Cushing's disease: clinical and healthrelated quality of life aspects. Eur J Endocrinol. 2012;167:311-326.

[14]Crespo I, Santos A, Webb SM. Quality of life in patients with hypopituitarism. Curr Opin Endocrinol Diabetes Obes. 2015. 22 (4):306-12.

[15]Azad TD, Veeravagu A, Kumar S, Katznelson L. Nelson Syndrome: Update on Therapeutic Approaches. World Neurosurg. 2015. 83 (6):113540. 